\title{
The effect of inhaled inactived Mycobacterium phlei as a treatment for asthma
}

\author{
MOYU MING, CHAOQIAN LI, ZHIXI LUO, SHENGQIU LV and QIXIANG SUN \\ Department of Respiratory Medicine, The First Affiliated Hospital of \\ Guangxi Medical University, Nanning, Guangxi 530021, P.R. China
}

Received October 23, 2015; Accepted November 21, 2016

DOI: $10.3892 / \mathrm{mmr} .2016 .6087$

\begin{abstract}
Allergic asthma is a chronic airway disorder characterized by airway inflammation, mucus hypersecretion, and airway hyperresponsiveness (AHR). A murine model of asthma was used to examine the antiasthmatic effect of inhaled inactived Mycobacterium phlei (M.phlei). AHR, neutrophil levels, eosinophil levels and levels of interleukin (IL)-17 and IL-23 receptor (IL-23R) were monitored. The results demonstrated that inactivated $M$. phlei alleviates the IL- $17^{+} \gamma \delta \mathrm{T}$ cell-mediated immune response and attenuates airway inflammation and airway hyperresponsiveness in the asthmatic murine lung, partially through inhibiting the expression of IL-23R. In conclusion, inactivated $M$. phlei may be an effective antiasthmatic treatment, regulating IL-17-producing $\gamma \delta \mathrm{T}$ (IL-17+ $\gamma \delta \mathrm{T}$ ) cell-mediated airway inflammation and airway hyperresponsiveness to relieve the symptoms of mice with asthma.
\end{abstract}

\section{Introduction}

Allergic asthma is a chronic airway disorder characterized by airway inflammation, mucus hypersecretion, and airway hyperresponsiveness (AHR) (1). The pro-inflammatory type 2 helper T (Th2) cell cytokines, interleukin (IL)-4, IL-5 and IL-13, which trigger the release of IgE from B lymphocytes and airway eosinophilia (2), may contribute to AHR in asthma (3). Asthma is most commonly associated with an aberrant Th 2 cell response, but severe disease is not exclusively associated with the production of Th2 cell-associated cytokines (4). It is instead characterized by increased production of the pro-inflammatory cytokine IL-17. Previous studies have suggested that IL-17 is involved in the pathogenesis of airway diseases, including allergic asthma, and IL-17 expression has

Correspondence to: Dr Chaoqian Li, Department of Respiratory Medicine, The First Affiliated Hospital of Guangxi Medical University, 6 Shuangyong Road, Nanning, Guangxi 530021, P.R. China

E-mail: chaoqianli123456@163.com

Key words: inhaled inactived Mycobacterium phlei, asthma, IL-17, IL-23R, $\gamma \delta$ T cell been revealed to be upregulated in the airways of mice and humans following allergen-induced airway inflammation (5-8). A neutrophilic influx is observed in the lung following IL-17 production, contributing to pulmonary diseases including asthma $(9,10)$. Therefore, there is accumulating evidence that IL-17 is associated with allergic asthma.

$\gamma \delta \mathrm{T}$ cells have been reported to be dominant producers of IL-17 at the site of infection during the early phase of pulmonary Mycobacterium tuberculosis infection (11). In addition, IL-17-producing $\gamma \delta \mathrm{T}$ (IL-17 ${ }^{+} \gamma \delta \mathrm{T}$ ) cells are associated with certain autoimmune diseases (12). IL- $17^{+} \gamma \delta \mathrm{T}$ cells are localized in mucosal tissues, including the lung, intestine, peritoneal cavity and reproductive organs, that are exposed to exogenous stimuli such as pathogens (13). Furthermore, several studies have reported that endogenous IL-23 induces IL-17 production by $\gamma \delta \mathrm{T}$ cells in vivo and in vitro (14-18).

It has previously been reported that IL-17, an important pro-inflammatory cytokine, was mainly produced by $\gamma \delta \mathrm{T}$ cells (19). $\gamma \delta \mathrm{T}$ cells are generated from naïve $\mathrm{T}$ cells, and $\gamma \delta \mathrm{T}$ cell differentiation is driven by stimuli including IL-23. IL-23- IL-23 receptor (IL-23R) signaling promotes GATA binding protein 3 (GATA-3) expression and enhances IL-17 production by $\gamma \delta$ T cells $(20,21)$. These cells are the first immune cells found in the fetus and confer immunity to newborns prior to activation of the adaptive immune system.

The Bacillus Calmette-Guérin (BCG) vaccine, a non-specific stimulator of immune function, protects against the development of asthma in humans and mice via inhibition of Th2 immune responses, which are characteristic of asthma (22-24). The BCG vaccine is considered safe, with side-effects mainly including erythema and a papule, ulcer or scar at the immunization site. These side-effects are mild and do not require treatment. However, regional suppurative lymphadenitis and osteitis are not uncommon.

Immunotherapy is the only currently available treatment with the potential to change the natural history of allergic disease and delay allergy progression in individuals with atopic allergies (24). Mucosal immunotherapy is advantageous due to the non-injection route of administration and lower side-effect profile (25). Multiple routes for mucosal immunotherapy have been proposed and investigated, including oral, nasal, tracheal and sublingual. Atomization delivery is attractive due to the ease of administration. It has previously been observed that inhalation of inactivated Mycobacterium phlei (M.phlei) attenuates 
airway inflammation via upregulation of IL-10 and interferon (IFN) $-\gamma$ secretion, which are anti-inflammatory molecules, and downregulation of IL-4 production (26). $\gamma \delta \mathrm{T}$ cells are generated from native $\mathrm{T}$ cells, and $\gamma \delta \mathrm{T}$ cell differentiation is driven by stimuli such as IL-23. IL-23-IL-23R signaling promotes GATA-3 expression and enhances IL-17 production by $\gamma \delta \mathrm{T}$ cells $(19,20)$. In general, $\gamma \delta \mathrm{T}$ cells account for $\sim 3-5 \%$ of all lymphoid cells found in the secondary lymphoid tissues and the blood. These cells are the first immune cells found in the fetus and provide immunity to newborns prior to activation of the adaptive immune system (27).

Therefore, the present study hypothesized that inactivated $M$. phlei, administrated via inhalation, would exert an antiasthmatic effect in a murine asthma model through suppression of the pro-inflammatory activity of IL- $17^{+} \gamma \delta \mathrm{T}$ cells by downregulation of IL-23R expression.

\section{Materials and methods}

Animals. Male BALB/c mice ( $\mathrm{n}=30$ ), 6-8 weeks old, weight 18-22 g, were obtained from the Laboratory Animal Center of Guangxi Medical University (Nanning, China), and housed under specific-pathogen-free conditions in a facility with an automatic 12/12 h day/night cycle and fed with a standard laboratory food and water. Mice were randomly assigned to three experimental groups ( $\mathrm{n}=10$ in each group): The normal control group (group A), the sensitized/M. phlei untreated group (group B) and the sensitized/M. phlei treated group (group C). Sensitization was brought about by challenge with ovalbumin to create a murine asthma model.

Establishment of a murine model of asthma. A murine model of asthma was established according to a modification of previous methods (26). Mice were sensitized via intraperitoneal injections of $25 \mu \mathrm{g}$ ovalbumin (OVA) and $1 \mathrm{mg} \mathrm{Al}(\mathrm{OH})_{3}$ suspended in $0.2 \mathrm{ml}$ saline on days 0,7 and 14. Following initial sensitization the mice were challenged for $20 \mathrm{~min}$ with $2 \%$ OVA once per day using an ultrasonic nebulizer (Model WH-2000; Guangdong Yuehua Medical Instrument Factory Co., Ltd., Guangdong, China) in a closed chamber on days 21-28. Group A mice received saline in place of OVA at the sensitization and challenge stages.

Following the challenge, the treatment group inhaled a solution of inactivated M. phlei (1.72 $\mu \mathrm{g}$ ampule M. phlei dissolved in $10 \mathrm{ml}$ saline; cat. no. S20040067; Chengdu Jinxing Jiankang Pharmaceutical Co., Ltd., Chengdu, China) administered by nebulizer once per day for 5 days. The normal control group and asthma model group (groups A and B) were sham treated with $10 \mathrm{ml}$ atomized saline instead. The animals were sacrificed by cervical dislocation $24 \mathrm{~h}$ after the final inactivated M. phlei treatment. Lung tissue was subsequently harvested: Left lobes were fixed with $10 \%$ formalin for hematoxylin and eosin (H\&E) staining and immunohistochemistry, while right lungs were stored at $-80^{\circ} \mathrm{C}$ until further use for fluorescence-activated cell sorting (FACS).

Measurement of $A H R$. Total lung resistance $\left(\mathrm{R}_{\mathrm{L}}\right)$, dynamic compliance (Cdyn) and peak expiratory flow (PEF) were assessed via a tracheostomy tube $3 \mathrm{~h}$ following the inhalation of saline or multiplied methacholine treatment as previously described, using a computerized small animal ventilator (Data Sciences International, Minneapolis, MN, USA) (28). Methacholine is used to diagnose asthma by inducing bronchoconstriction. Mice were allowed to stabilize on the ventilator for $5 \mathrm{~min}$ prior to measurements. Once stabilized, dose responsiveness to methacholine $(6.25,12.5,25$ and $50 \mathrm{mg} / \mathrm{ml})$ was measured and reported as total lung resistance.

Pulmonary histological analysis. Lungs were harvested from the mice. Left lobes were fixed with $10 \%$ formalin for $24 \mathrm{~h}$ and embedded in paraffin for histopathology analysis. 4-5 $\mu \mathrm{m}$ sections were cut. The tissue sections underwent H\&E staining to visualise airway inflammation changes through light microscopy (Olympus Corporation, Tokyo, Japan).

Bronchoalveolar lavage fluid cell counting. Bronchoalveolar lavage fluid (BALF) was isolated as previously described (2). BALF was centrifuged at $600 \mathrm{x}$ g for $5 \mathrm{~min}$, and the supernatant was discarded. The cell pellet was resuspended in $200 \mu \mathrm{l}$ of RPMI-1640 medium (cat. no. 11875093; Thermo Fisher Scientific, Inc., Waltham, MA, USA), and the red blood cells were lysed using $200 \mu 1$ Red Blood Cell Lysis Buffer (cat. no. R1010; Beijing Solarbio Science and Technology Co., Ltd., Beijing, China). The cells were subsequently adhered to a hemocytometer slide and counted at X100 magnification with a light microscope. The absolute cell counts per BALF sample were calculated for neutrophils and eosinophils.

Immunohistochemistry examination of IL-17 and IL-23 receptor $(I L-23 R)$. For immunohistochemical detection of IL-17 and IL-23R in the airway, formalin-fixed, paraffin-embedded sections were stained with biotinylated polyclonal antibodies specific for IL-17 (cat. no. 500-P07Bt; PeproTech, Inc., Rocky Hill, NJ, USA) and IL-23R (cat. no. BAF1400; R\&D Systems, Inc., Minneapolis, MN, USA). Negative control experiments were performed by omitting the primary antibodies. Sections were blocked with $3 \%$ bovine serum albumin and $0.4 \%$ Triton X-100 in TBS buffer for $30 \mathrm{~min}$ at room temperature, then incubated overnight at $4^{\circ} \mathrm{C}$ with IL-17 antibody and IL-23R antibodies at 1:50 dilutions, with the subsequent addition of a peroxidase complex prepared according to the manufacturer's instructions. Image analysis was then performed and analysed with Lecia LAS AF software version 2.6.0 (Leica Microsystems $\mathrm{GmbH}$, Wetzlar, Germany).

Flow cytometric analysis. The following antibodies were used for flow cytometric analysis of BALF-derived T cells: PERCP-CY5.5-conjugated IL-17 antibody (cat. no. TC11-18H10; BD Pharmingen, San Diego, CA, USA), IL-23R polyclonal antibody (cat. no. 06-1331; Merck Millipore, Darmstadt, Germany) and goat anti-rabbit IgG-PE (cat. no. sc-3739; Santa Cruz Biotechnology, Inc., Dallas, TX, USA). Intracellular cytokine detection of BALF-derived $\mathrm{T}$ cells was performed as previously described (29).

Statistical analysis. Data are expressed as the mean \pm standard deviation. Statistical analysis was performed via one-way analysis of variance for multiple comparisons, followed by Fisher's Least Significant Difference test for comparisons 


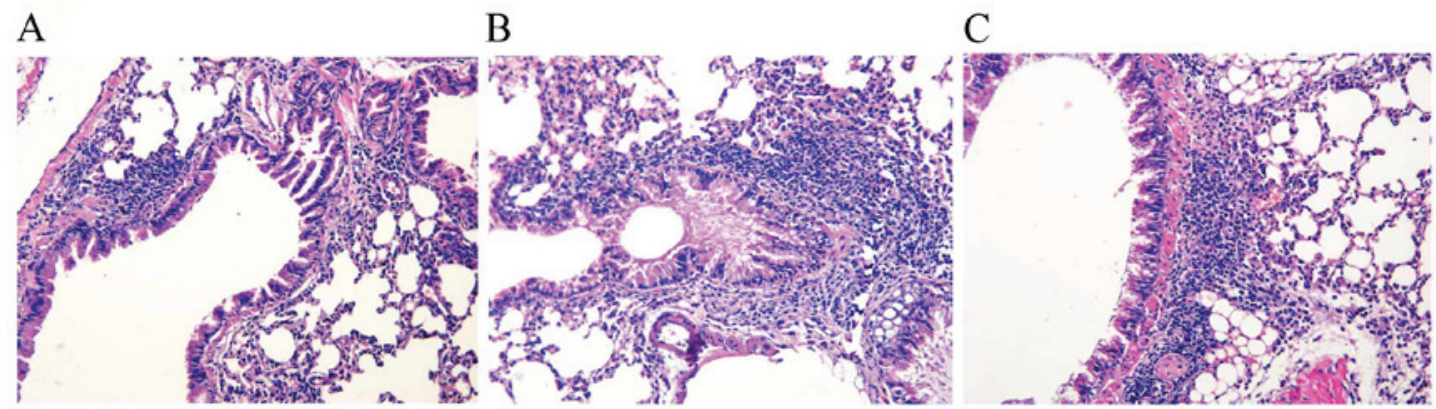

Figure 1. Effects of inactivated Mycobacterium phlei (M.phlei) on ovalbumin-induced airway inflammation. Histological examination of lung tissue by haemotoxylin and eosin staining in the (A) normal control group, (B) sensitized/M. phlei untreated group and (C) sensitized/M. phlei treated group. Original magnification, $\mathrm{x} 400$.

A

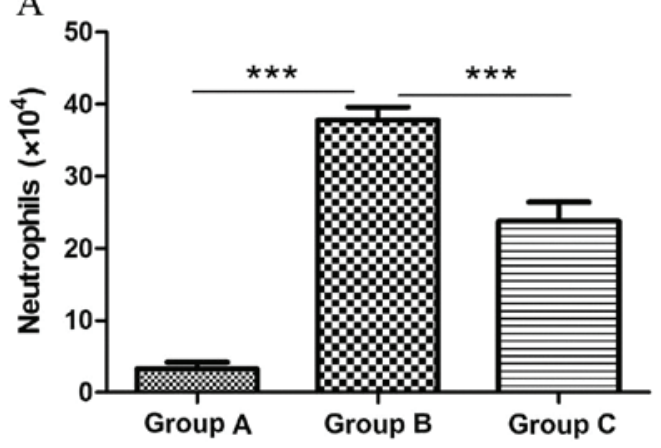

B

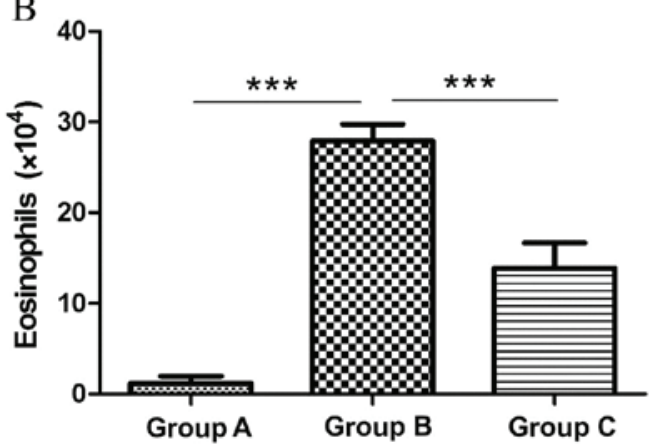

Figure 2. Effects of inactivated Mycobacterium phlei (M.phlei) on (A) neutrophil and (B) eosinophil numbers in bronchoalveolar lavage fluid. Data are presented as the mean \pm standard error with comparisons indicated by lines; ${ }^{* * *} \mathrm{P}<0.001$. Group A is the normal control group, group B is the sensitized/M. phlei untreated group and group $\mathrm{C}$ is the sensitized/M. phle $i$ treated group.

between groups. $\mathrm{P}<0.05$ was considered to indicate a statistically significant difference.

\section{Results}

Effects of inactivated M. phlei on the pulmonary pathology of OVA-induced asthmatic mice. To determine the effect on the lung parenchyma following inactivated $M$. phlei treatment, formalin-fixed, paraffin-embedded whole lungs were sectioned and stained with H\&E. The lung histology demonstrated increased numbers of inflammatory cells within the bronchiolar and alveolar compartments, as well cell hyperplasia, in the two sensitized groups compared with the normal control group. Predominately perivascular and peribronchiolar mixed eosinophil and lymphocyte cellular aggregates were consistently observed following OVA challenge and were not observed in the normal control group. Thickened basement membranes were present in the sensitized groups vs. the normal control group (Fig. 1A and B). The administration of inactivated $M$. phlei attenuated the infiltration of inflammatory cells in the peribronchial and perivascular areas as compared with the asthma model mice, with fewer inflammatory eosinophil and lymphocyte cellular aggregates in the sensitized/M.phlei treated group compared with the sensitized/M. phlei untreated group (Fig. 1B and C).

Effect of inhaled inactived M. phlei on neutrophils and eosinophils in BALF. Neutrophil numbers were significantly elevated in the sensitized/M. phlei untreated group (37.8x10 Fig. 2A) compared with the normal control group $\left(3.3 \times 10^{4}\right.$; 10.45-fold; P<0.0001; Fig. 2A). However neutrophil numbers were significantly decreased in the sensitized $/ M$. phlei treated group compared with the sensitized/M. phlei untreated group (1.59-fold difference; $\mathrm{P}<0.0001$; Fig. 2A). Eosinophil numbers were significantly increased in sensitized/M. phlei untreated mice $\left(27.9 \times 10^{4}\right.$; Fig. 2B) compared with the normal control group $\left(1.17 \times 10^{4} ; 23.8\right.$ fold difference; $\mathrm{P}<0.0001$; Fig. $\left.2 \mathrm{~B}\right)$. A 2 -fold decrease in eosinophil numbers was observed in the sensitized/M. phlei treated group (13.9x10 ; Fig. 2B) compared with the sensitized $/ M$. phlei untreated group $(\mathrm{P}<0.0001$; Fig. 2B). The results suggest that inactived $M$. phlei may attenuate the airway inflammation of mice with asthma.

Effect of inhaled inactived M. phlei on lung function alongside methacholine treatment in asthmatic mice. The effect of inhaled inactived M. phlei on AHR to methacholine in asthmatic mice was evaluated through measuring changes in $\mathrm{R}_{\mathrm{L}}$, Cdyn and PEF.

$\mathrm{PEF}$ is the maximum flow rate during expiration, measured in $\mathrm{ml} / \mathrm{s}$ (Fig. 3A). OVA challenge significantly decreased PEF in the sensitized/M. phlei untreated group compared with the normal control group at $0 \mathrm{mg} / \mathrm{ml}$ methacholine $(\mathrm{P}=0.0038$; Fig. $3 \mathrm{~A})$, and at $12.5 \mathrm{mg} / \mathrm{ml}$ methacholine ( $\mathrm{P}=0.0146$; Fig. $3 \mathrm{~A})$. Sensitized/M.phlei treated mice demonstrated significantly elevated PEF compared with sensitized/M. phle $i$ untreated mice at $0 \mathrm{mg} / \mathrm{ml}$ methacholine 

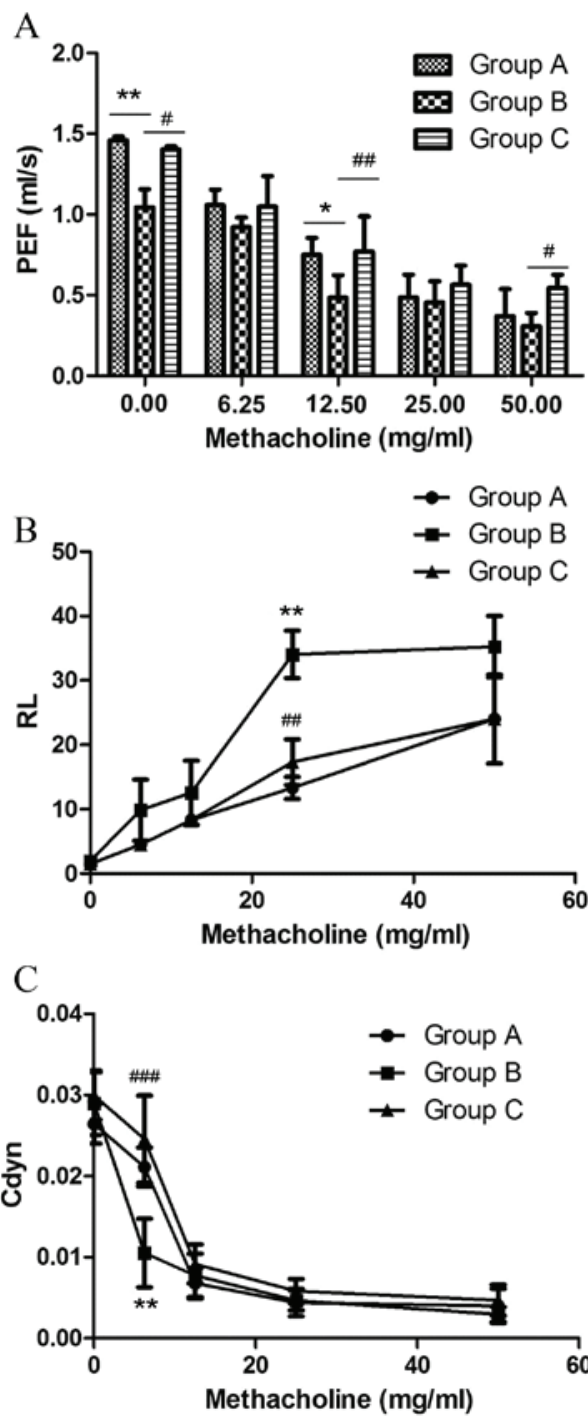

Figure 3. Effects of inhaled inactived Mycobacterium phlei (M.phlei) on airway hyperresponsiveness with methacholine treatment. PEF, RL and Cdyn are expressed as percentage change from the baseline value. (A) Effects of inhaled inactived M. phlei on PEF. (B) Effects of inhaled inactived M. phlei on $\mathrm{R}_{\mathrm{L}}$. OVA challenge significantly increased $\mathrm{R}_{\mathrm{L}}$ at all 4 methacholine doses with the maximum increase at $25 \mathrm{mg} / \mathrm{ml}$. (C) Effects of inhaled inactived $M$. phlei on Cdyn. Data are presented as the mean \pm standard deviation. Group A is the normal control group, group B is the sensitized/M. phle untreated group and group $\mathrm{C}$ is the sensitized $/ M$. phle $i$ treated group. ${ }^{*} \mathrm{P}<0.05,{ }^{* *} \mathrm{P}<0.01,{ }^{* * *} \mathrm{P}<0.001$ vs. group $\mathrm{A} .{ }^{\#} \mathrm{P}<0.05,{ }^{\# \#} \mathrm{P}<0.01$ and ${ }^{\# \# \#} \mathrm{P}<0.001$ vs. group B. PEF, peak expiratory flow; $\mathrm{R}_{\mathrm{L}}$, total lung resistance; Cdyn, dynamic compliance.

( $\mathrm{P}=0.0139$; Fig. 3A), $12.5 \mathrm{mg} / \mathrm{ml}$ methacholine $(\mathrm{P}=0.00375$; Fig. 3A) and $50 \mathrm{mg} / \mathrm{ml}$ methacholine ( $\mathrm{P}=0.0142$; Fig. 3A). No significant difference ws observed in PEF between sensitized $/ M$. phlei treated and normal control groups (Fig. 3A). These results demonstrate that inhaled inactived M. phlei attenuates the impairment to PEF caused by methacholine in a mouse model of asthma.

OVA challenge significantly increased $\mathrm{R}_{\mathrm{L}}$ at all 4 methacholine doses tested in sensitized $/ M$. phlei untreated mice, with the maximum increase at $25 \mathrm{mg} / \mathrm{ml}(\mathrm{P}=0.001$ vs. normal control group; $\mathrm{P}=0.06$ vs. sensitized $/ M$. phle $i$ treated group; Fig. 3B). The $\mathrm{R}_{\mathrm{L}}$ of the normal control group and the sensitized/M. phle $i$ treated group also increased in response
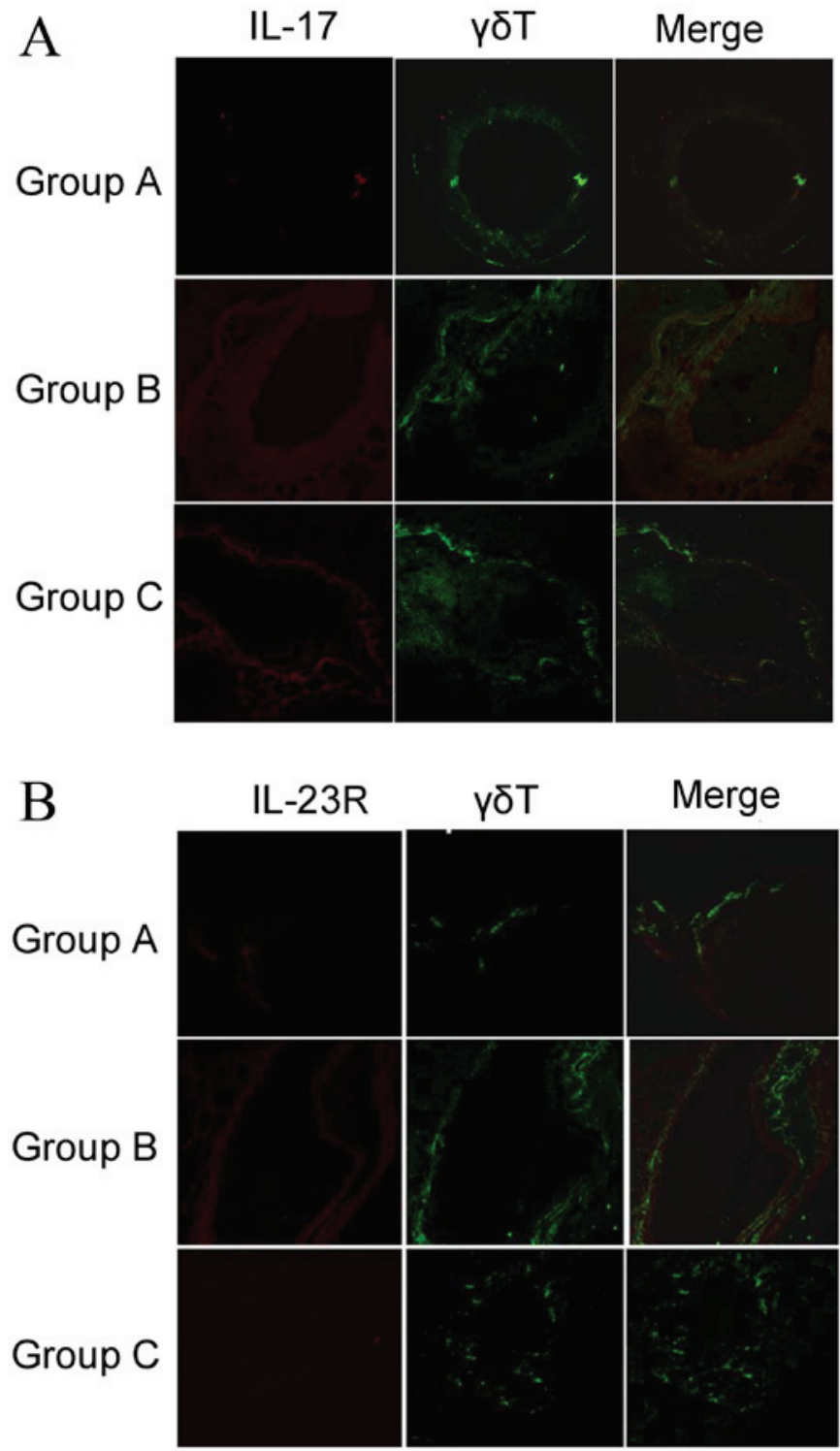

Figure 4. Effects of inhaled inactived Mycobacterium phlei (M.phlei) on inflammatory cytokine levels in lung tissues, visualized by immunofluorescence. The expression level of (A) IL-17 and (B) IL-23R in $\gamma \delta$ T cells. Group A is the normal control group, group B is the sensitized $/ M$. phlei untreated group and group $\mathrm{C}$ is the sensitized/M. phle $i$ treated group. Original magnification, x400. IL-17, interleukin-17; IL-23R, interleukin-23 receptor.

to methacholine doses, but there was no significant difference between these two groups (Fig. 3B).

A dose of $6.25 \mathrm{mg} / \mathrm{ml}$ methacholine significantly decreased Cdyn in the sensitized/M. phlei untreated group compared with the normal control group $(\mathrm{P}=0.02$; Fig. 3C) and the sensitized/M. phlei treated group $(\mathrm{P}<0.0001$; Fig. 3C) at a dose of $6.25 \mathrm{mg} / \mathrm{ml}$ methacholine. Other methacholine doses demonstrated no significant difference among the 3 groups. There was also no significant difference between the normal control group and the sensitized/M. phlei treated group at any dose (Fig. 3C).

These results demonstrate that an atomized solution of inactivated $M$. phlei treatment restored these 3 aspects close to the levels recorded in healthy control mice. The atomized solution of inactivated M. phlei can suppress the adverse impact of methacholine, and recover pulmonary function almost to the healthy level. 
A
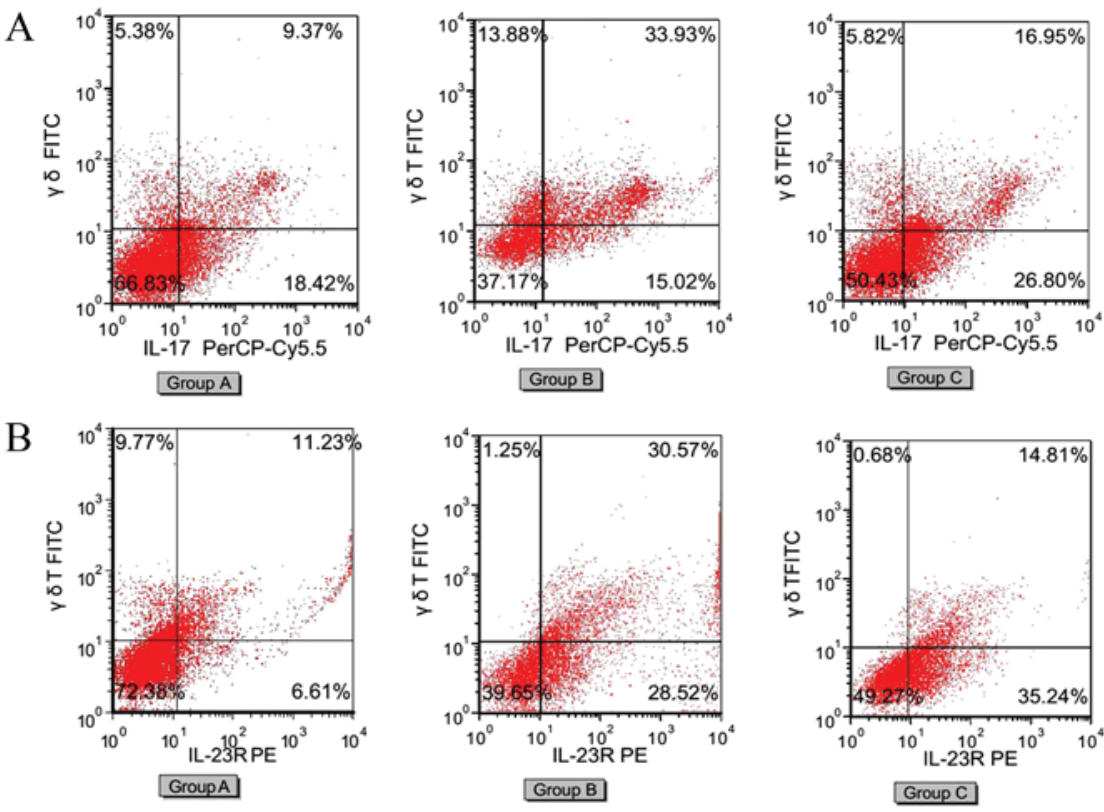

C

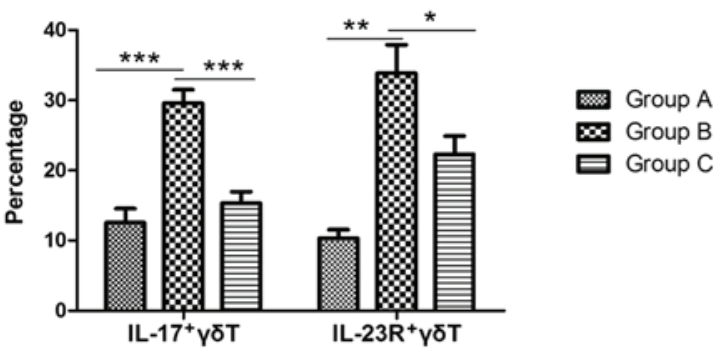

Figure 5. Effects of inhaled inactived Mycobacterium phlei $\left(M\right.$. phlei) on the production of IL-17 $7^{+} \gamma \delta \mathrm{T}$ and IL-23R ${ }^{+} \gamma \delta \mathrm{T}$ cells. Production of $(\mathrm{A})$ IL-17 $\gamma^{+} \delta \mathrm{T}$ cells and (B) IL-23R ${ }^{+} \gamma \delta \mathrm{T}$ cells was assessed by fluorescence associated cell sorting analysis. (C) Quantitative analysis of the percentage of IL-17 $\gamma \delta T$ or IL-23R ${ }^{+} \gamma \delta \mathrm{T}$ cells. Data are presented as the mean \pm standard deviation and comparisons are indicated with lines: ${ }^{*} \mathrm{P}<0.05$, ${ }^{* *} \mathrm{P}<0.01,{ }^{* * *} \mathrm{P}<0.001$. Group $\mathrm{A}$ is the normal control group, group B is the sensitized/M. phlei untreated group and group C is the sensitized/M. phlei treated group. IL-17, interleukin-17; IL-23R, interleukin-23 receptor.

Effects of inhaled inactived $M$. phlei on inflammatory cytokine levels in lung tissues, visualized with immunofluorescence. Expression of IL-17 and IL-23R in lung tissues of the three groups was determined by immunohistochemical staining, with images acquired using laser scanning confocal microscopy as described in materials and methods. IL-17 and IL-23R expression appeared to increase in the sensitized/M. phlei untreated group, but decreased with administration of inactived $M$. phlei (Fig. 4). These results demonstrate that reduction of IL-17 and IL-23R may be related to the antiasthmatic effect of inactived $M$. phlei in mice with asthma.

Effects of inhaled inactived M. phlei on the production of IL-17 or IL-23R positive $\gamma \delta T$ cells with FACS. FACS was performed to determine the ratio of IL-17 positive $\gamma \delta \mathrm{T}\left(\mathrm{IL}-17^{+} \gamma \delta \mathrm{T}\right)$ cells (Fig. 5A) and IL-23R positive $\gamma \delta \mathrm{T}\left(\mathrm{IL}^{2} 23 \mathrm{R}^{+} \gamma \delta \mathrm{T}\right)$ cells (Fig. 5B). The percentage of IL-17+ $\gamma \delta \mathrm{T}$ cells and IL-23R ${ }^{+} \gamma \delta \mathrm{T}$ cells significantly increased in the sensitized/M. phle $i$ untreated group compared with the normal control group $(\mathrm{P}<0.0001$ and $\mathrm{P}<0.0001$, respectively; Fig. 5C). However, in the sensitized/M. phlei treated group, the percentages of IL- $17^{+} \gamma \delta \mathrm{T}$ cells and IL-23R $\mathrm{R}^{+} \gamma \delta \mathrm{T}$ cells were significantly decreased compared with the sensitized/M. phlei untreated group $(\mathrm{P}<0.0001$ and $\mathrm{P}=0.015$, respectively; Fig. 5C). This reduction of IL-17 ${ }^{+} \gamma \delta \mathrm{T}$ cells and IL-23R ${ }^{+} \gamma \delta \mathrm{T}$ cells indicates that inflammation was attenuated and lung-function partially recovered. In addition, from the immunofluorescence detection (Fig. 4) and cell sorting (Fig. 5) results, it is possible to conclude that the antiasthmatic effect of inhaled inactived M. phlei is the result of the inhibition IL-17 and IL-23R expression, which decreases production of IL-17+ $\gamma \delta \mathrm{T}$ cells and IL-23R $\mathrm{R}^{+} \gamma \delta \mathrm{T}$ cells.

\section{Discussion}

Previous studies have demonstrated that inactivated $M$. phlei nebulized therapy is effective in adults and children aged 4-12 years with moderate persistent asthma $(30,31)$, however the detailed mechanism remains unclear. The results of the present study indicate that inhaled administration of inactivated $M$. phlei is able to alleviate allergen-induced airway inflammation in OVA-challenged mice. In addition, methacholine-associated damage is prevented in these mice by inhaled inactived $M$. phlei treatment, and pulmonary function is restored to close to the level of healthy mice. Therefore, inhaled inactived $M$. phlei may be an effective treatment for asthma. 
Although it is widely accepted that the pathognomonic features of asthma are mediated mainly by Th2 cells and their associated cytokines, increasing evidence suggest IL-17, an important pro-inflammatory cytokine that is mainly produced by $\gamma \delta T$ cells, is involved in the development of asthma (32). It has been demonstrated that IL-17 is expressed in the airway of patients with asthma $(7,10)$ and correlates with airway hyperresponsiveness $(21,33,34)$.

The present study has clearly demonstrated that inhaled administration of inactivated $M$. phlei suppresses production of IL-17-producing $\gamma \delta \mathrm{T}$ cells and decreased IL-23R-producing $\gamma \delta \mathrm{T}$ cells in the lungs of treated mice (Fig. 5).

IL-23 is important for the maintenance of IL-17 production, however, pathogen products and environmental signals can also regulate IL-17-producing $\gamma \delta \mathrm{T}$ cells, particularly Mycobacterium. Therefore, IL-17 production is complicated by the involvement of multiple immune mediators. Previous studies have demonstrated that combining $\mathrm{C}-\mathrm{C}$ motif chemokine receptor 6 and CD44 for FACS sorting of $\gamma \delta \mathrm{T}$ cells yielded an almost $100 \%$ pure population of IL-17-producing cells, indicating that $\gamma \delta T$ cells can be the sole source of IL-17 (21). Toll-like receptor triggering of $\gamma \delta \mathrm{T}$ cells provides the first source of IL-17 (21). Cytokine IL-6 is responsible for the development, activation and recruitment of IL-1 $17^{+} \gamma \delta \mathrm{T}$ cells (35). IL-21 may also be involved in the development of IL-17 $\gamma \delta$ T cells (36). In addition, AHR-mediated environmental signals can shape the functional capacity of IL-17 ${ }^{+} \gamma \delta \mathrm{T}$ cells (21). However, a number of mechanisms of the inhibitory effect of M.phlei on IL-17 ${ }^{+} \gamma \delta \mathrm{T}$ cells remain to be identified.

In conclusion, the current study demonstrates that inactivated $M$. phlei acts as an immune regulator of the IL- $17^{+} \gamma \delta \mathrm{T}$-mediated response in the lung. Inactivated M.phlei suppresses the IL-17 $\gamma \delta$ T-mediated immune response, airway inflammation and airway hyperresponsiveness in the lung, at least partially inhibiting the expression of IL-23R. Therefore, inactivated $M$. phlei may be an effective strategy for regulating IL- $17^{+} \gamma \delta \mathrm{T}$-mediated airway inflammation and airway hyperresponsiveness. This may, therefore, represent an effective treatment strategy for asthma.

\section{Acknowledgements}

The present study was funded by the National Natural Science Foundation of China (grant no. 81360007).

\section{References}

1. Galli SJ, Tsai M and Piliponsky AM: The development of allergic inflammation. Nature 454: 445-454, 2008.

2. Ming M, Luo Z, Lv S and Li C: Inhalation of inactivated-Mycobacterium phlei prevents asthma-mediated airway hyperresponsiveness and airway eosinophilia in mice by reducing IL-5 and IL-13 levels. Mol Med Rep 14: 5343-5349, 2016.

3. Cockcroft DW and Davis BE: Mechanisms of airway hyperresponsiveness. J Allergy Clin Immunol 118: 551-559; quiz 560-1, 2006.

4. Hofmann MA, Kiecker F and Zuberbier T: A systematic review of the role of interleukin-17 and the interleukin-20 family in inflammatory allergic skin diseases. Curr Opin Allergy Clin Immunol 16: 451-457, 2016.

5. Kawaguchi M, Onuchic LF, Li XD, Essayan DM, Schroeder J, Xiao HQ, Liu MC, Krishnaswamy G, Germino G and Huang SK: Identification of a novel cytokine, ML-1, and its expression in subjects with asthma. J Immunol 167: 4430-4435, 2001.
6. Hellings PW, Kasran A, Liu Z, Vandekerckhove P, Wuyts A Overbergh L, Mathieu C and Ceuppens JL: Interleukin-17 orchestrates the granulocyte influx into airways after allergen inhalation in a mouse model of allergic asthma. Am J Respir Cell Mol Biol 28: 42-50, 2003.

7. Molet S, Hamid Q, Davoineb F, Nutku E, Taha R, Pagé N, Olivenstein R, Elias J and Chakir J: IL-17 is increased in asthmatic airways and induces human bronchial fibroblasts to produce cytokines. J Allergy Clin Immunol 108: 430-438, 2001.

8. Shen F, Zhao MW, He B, Wang YZ and Yao WZ: The levels and clinical implications of induced sputum interleukin-17 in chronic obstructive pulmonary disease and asthma. Zhonghua Nei Ke Za Zhi 43: 888-890, 2004 (In Chinese).

9. Liang SC, Long AJ, Bennett F, Whitters MJ, Karim R, Collins M, Goldman SJ, Dunussi-Joannopoulos K, Williams CM, Wright JF and Fouser LA: An IL-17F/A heterodimer protein is produced by mouse Th17 cells and induces airway neutrophil recruitment. J Immunol 179: 7791-7799, 2007.

10. Barczyk A, Pierzchala W and Sozañska E: Interleukin-17 in sputum correlates with airway hyperresponsiveness to methacholine. Respir Med 97: 726-733, 2003.

11. Lockhart E, Green AM and Flynn JL: IL-17 production is dominated by gammadelta T cells rather than CD4 T cells during Mycobacterium tuberculosis infection. J Immunol 177: 4662-4669, 2006.

12. Lu H, Li DJ and Jin LP: $\gamma \delta T$ Cells and Related Diseases. Am J Reprod Immunol 75: 609-618, 2016.

13. Shibata K and Yoshikai Y: Functions of IL-17-producing $\gamma \delta$ T Cells. Open Immunology Journal 2: 151-155, 2009.

14. Stark MA, Huo Y, Burcin TL, Morris MA, Olson TS and Ley K: Phagocytosis of apoptotic neutrophils regulates granulopoiesis via IL-23 and IL-17. Immunity 22: 285-294, 2005.

15. Nakamura R, Shibata K, Yamada H, Shimoda K, Nakayama K and Yoshikai Y: Tyk2-signaling plays an important role in host defense against Escherichia coli through IL-23-induced IL-17 production by gammadelta T cells. J Immunol 181: 2071-2075, 2008.

16. Saunus JM, Wagner SA, Matias MA, Hu Y, Zaini ZM and Farah CS: Early activation of the interleukin-23-17 axis in a murine model of oropharyngeal candidiasis. Mol Oral Microbiol 25: 343-356, 2010.

17. Aggarwal S, Ghilardi N, Xie MH, de Sauvage FJ and Gurney AL: Interleukin-23 promotes a distinct CD4 T cell activation state characterized by the production of interleukin-17. J Biol Chem 278: 1910-1914, 2003.

18. Sutton CE, Lalor SJ, Sweeney CM, Brereton CF, Lavelle EC and Mills KH: Interleukin-1 and IL-23 induce innate IL-17 production from gammadelta T cells, amplifying Th17 responses and autoimmunity. Immunity 31: 331-341, 2009.

19. Zhong Q, Zhou K, Liang QL, Lin S, Wang YC, Xiong XY, Meng ZY, Zhao T, Zhu WY, Yang YR, et al: Interleukin-23 secreted by activated macrophages drives $\gamma \delta \mathrm{T}$ cell production of interleukin-17 to aggravate secondary injury after intracerebral hemorrhage. J Am Heart Assoc 5: pii: e004340, 2016.

20. Sutton CE, Mielke LA and Mills KH: IL-17producing $\gamma \delta$ T cells and innate lymphoid cells. Eur J Immunol 42: 2221-2231, 2012.

21. Martin B, Hirota K, Cua DJ, Stockinger B and Veldhoen M: Interleukin-17-producing gammadelta $\mathrm{T}$ cells selectively expand in response to pathogen products and environmental signals. Immunity 31: 321-330, 2009.

22. Robinson DS, Hamid Q, Ying S, Tsicopoulos A, Barkans J, Bentley AM, Corrigan C, Durham SR and Kay AB: Predominant TH2-like bronchoalveolar T-lymphocyte population in atopic asthma. N Engl J Med 326: 298-304, 1992.

23. Kon OM and Kay AB: T cells and chronic asthma. Int Arch Allergy Immunol 118: 133-135, 1999.

24. Nagai $H$, Teramachi $H$ and Tuchiya $T$ : Recent advances in the development of anti-allergic drugs. Allergol Int 55: 35-42, 2006.

25. Ye YL, Chuang YH and Chiang BL: Strategies of mucosal immunotherapy for allergic diseases. Cell Mol Immunol 8: 453-461, 2011.

26. Zhang J, Li C and Guo S: Effects of inhaled inactivated Mycobacterium phlei on airway inflammation in mouse asthmatic models. J Aerosol Med Pulm Drug Deliv 25: 96-103, 2012.

27. Sinkora M, Sinkorová J and Holtmeier W: Development of gammadelta thymocyte subsets during prenatal and postnatal ontogeny. Immunology 115: 544-555, 2005.

28. Poole JA, Wyatt TA, Romberger DJ, Staab E, Simet S, Reynolds SJ, Sisson JH and Kielian T: MyD88 in lung resident cells governs airway inflammatory and pulmonary function responses to organic dust treatment. Respir Res 16: 111, 2015. 
29. Nakasone C, Yamamoto N, Nakamatsu M, Kinjo T, Miyagi K, Uezu K, Nakamura K, Higa F, Ishikawa H, O'brien RL, et al: Accumulation of gamma/delta $\mathrm{T}$ cells in the lungs and their roles in neutrophil-mediated host defense against pneumococcal infection. Microbes Infect 9: 251-258, 2007.

30. Zhang J, Guo S, Li C and Jiang X: Therapeutic effects of inhaled inactivated Mycobacterium phlei in adult patients with moderate persistent asthma. Immunotherapy 4: 383-387, 2012.

31. Ming M, Li C, Luo Z and Lv S: Effect of inhaled inactivated Mycobacterium phlei in children with moderate asthma. Immunotherapy 5: 191-197, 2013.

32. Nakada EM, Shan J, Kinyanjui MW and Fixman ED: Adjuvant-dependent regulation of interleukin-17 expressing $\gamma \delta \mathrm{T}$ cells and inhibition of Th2 responses in allergic airways disease. Respir Res 15: 90, 2014.
33. O'Brien RL, Roark CL and Born WK: IL-17-producing gammadelta T cells. Eur J Immunol 39: 662-666, 2009.

34. Roark CL, Simonian PL, Fontenot AP, Born WK and O'Brien RL: gammadelta T cells: An important source of IL-17. Curr Opin Immunol 20: 353-357, 2008.

35. Lochner M, Peduto L, Cherrier M, Sawa S, Langa F, Varona R, Riethmacher D, Si-Tahar M, Di Santo JP and Eberl G: In vivo equilibrium of proinflammatory $\mathrm{IL}-17^{+}$and regulatory IL- $10^{+}$ Foxp3 $^{+}$RORgamma t ${ }^{+}$T cells. J Exp Med 205: 1381-1393, 2008. 36. Nurieva R, Yang XO, Martinez G, Zhang Y, Panopoulos AD, Ma L, Schluns K, Tian Q, Watowich SS, Jetten AM and Dong C: Essential autocrine regulation by IL-21 in the generation of inflammatory T cells. Nature 448: 480-483, 2007. 